\title{
ARTICLE
}

Clinical Research

\section{Safety and preliminary immunogenicity of JNJ-64041809, a live- attenuated, double-deleted Listeria monocytogenes-based immunotherapy, in metastatic castration-resistant prostate cancer}

\author{
Charles G. Drake $\mathbb{D}^{1,11} \cdot$ Russell K. Pachynski ${ }^{2}$ Sumit K. Subudhi $\mathbb{1}^{3} \cdot$ Douglas G. McNeel $\mathbb{1}^{4}$. \\ Emmanuel S. Antonarakis ${ }^{5}$ - Todd M. Bauer ${ }^{6} \cdot$ Peter Lauer $^{7}$ - Dirk Brockstedt ${ }^{7}$ - Daniel Patricia ${ }^{8}$ Mark Wade $^{8}$. \\ Enrique Zudaire ${ }^{8}$. Nibedita Bandyopadhyay ${ }^{9} \cdot$ Dolly A. Parasrampuria $^{8} \cdot$ Suzette Girgis $^{8} \cdot$ Gary E. Mason $^{8}$. \\ Roland E. Knoblauch ${ }^{8} \cdot$ Nicole Stone ${ }^{8} \cdot$ Jeffrey R. Infante ${ }^{8} \cdot$ Marco M. Gottardis $^{8} \cdot$ Lawrence Fong $^{10}$
}

Received: 14 December 2020 / Revised: 6 May 2021 / Accepted: 27 May 2021 / Published online: 13 July 2021

(c) The Author(s) 2021. This article is published with open access

\begin{abstract}
Background The safety and immunogenicity of JNJ-64041809 (JNJ-809), a live-attenuated, double-deleted Listeria monocytogenes (LADD Lm)-based immunotherapy targeting 4 relevant prostate cancer antigens, was evaluated in a phase 1 study in patients with metastatic castration-resistant prostate cancer (mCRPC).

Methods Men with progressive mCRPC who had received $\geq 2$ prior approved therapies were enrolled. Primary study objectives were to determine the recommended phase 2 dose (RP2D) and to evaluate the safety and immunogenicity of JNJ-809.

Results A total of 26 patients received JNJ-809 $\left(1 \times 10^{8} \mathrm{CFU}(n=6) ; 1 \times 10^{9} \mathrm{CFU}(n=20)\right)$. No dose-limiting toxicities were reported, and $1 \times 10^{9} \mathrm{CFU}$ was selected as the RP2D. The most common adverse events (AEs) reported were chills (92\%), pyrexia (81\%), and fatigue (62\%). The most frequent grade $\geq 3$ AEs were lymphopenia (27\%) and hypertension $(23 \%)$. Serious AEs were reported in $27 \%$ of patients including 1 patient with grade 3 intestinal obstruction. JNJ-809 transiently induced peripheral cytokines, including interferon- $\gamma$, interleukin-10, and tumor necrosis factor- $\alpha$. Of the 7 patients evaluable for $\mathrm{T}$ cell responses at the $1 \times 10^{9} \mathrm{CFU}$ dose, evidence of post-treatment antigenic responses were observed in 6 to the Listeria antigen listeriolysin $\mathrm{O}$ and in 5 to $\geq 1$ of the 4 encoded tumor antigens. Best overall response was stable disease in 13/25 response-evaluable patients. The study was terminated early as data collected were considered sufficient to evaluate safety and immunogenicity.

Conclusions JNJ-809 has manageable safety consistent with other LADD Lm-based therapies. Limited antigen-specific immune responses were observed, which did not translate into objective clinical responses.
\end{abstract}

Supplementary information The online version contains supplementary material available at https://doi.org/10.1038/s41391021-00402-8.

Charles G. Drake

cdrake2@its.jnj.com

Columbia University Medical Center, New York, NY, USA

2 Washington University of St. Louis, St. Louis, MO, USA

3 The University of Texas MD Anderson Cancer Center, Houston, TX, USA

4 University of Wisconsin Carbone Cancer Center, Madison, WI, USA

5 Johns Hopkins Kimmel Medical Institute, Baltimore, MD, USA

\section{Introduction}

Prostate cancer is among the leading causes of new cancer diagnoses $(7.1 \%)$ and the fifth leading cause of cancer death

6 Sarah Cannon Research Institute/Tennessee Oncology, PLLC, Nashville, TN, USA

7 Aduro Biotech, Berkeley, CA, USA

8 Janssen Research \& Development, Spring House, PA, USA

9 Janssen Research \& Development, Raritan, NJ, USA

10 UCSF Helen Diller Family Comprehensive Cancer Center, San Francisco, CA, USA

11 Present address: Janssen Research \& Development, Spring House, PA, USA 
in men $(3.8 \%)$ worldwide [1]. Localized prostate cancer is managed by active surveillance for patients with low-risk disease, higher risk localized disease is treated with either radical prostatectomy or radiation therapy. These treatments can be curative for some patients, but approximately $20-40 \%$ of men who undergo radical prostatectomy and $30-50 \%$ of men treated with radiation therapy will develop biochemical recurrence [2, 3]. Salvage radiotherapy/prostatectomy and/or androgen deprivation therapy are viable treatment options for biochemically recurrent prostate cancer [4]; however, the majority of patients will eventually develop metastatic castration-resistant prostate cancer (mCRPC). Patients can also develop de novo metastatic castration-sensitive prostate cancer, a more aggressive cancer that is associated with worse prognosis as compared with prostate cancer that metastasizes after initial diagnosis $[5,6]$. Next-generation hormonal therapies (NHTs) have improved clinical outcomes in mCRPC [7-10], but as with other treatments, NHTs are limited by primary or acquired resistance [11-13], highlighting the need for novel effective therapies.

Immunotherapeutic approaches to treating prostate cancer have had limited success. Currently, two immunotherapies are approved for the treatment of prostate cancer: sipuleucel-T, an autologous cellular immunotherapy targeting prostatic acid phosphatase (PAP) for the treatment of asymptomatic or minimally symptomatic mCRPC and pembrolizumab, an immune checkpoint inhibitor (ICI) for treatment of microsatellite instability-high or mismatch repair-deficient prostate cancer in patients who have exhausted available therapies $[14,15]$. A challenge in developing immunotherapies for prostate cancer has been the multiple immune evasion mechanisms, including decreased major histocompatibility complex (MHC) class I expression and increased infiltration of regulatory $\mathrm{T}$ cells (Tregs) and myeloid-derived suppressor cells (MDSCs) [16-19]. Given the immunosuppressive tumor microenvironment of "cold" tumors such as prostate cancer tumors, response to ICIs has been poor. In two phase 3 studies of ipilimumab in patients with prostate cancer, no survival benefit over placebo was observed [20,21], and in a phase 1 study of nivolumab in CRPC, no objective responses were reported [22].

The live-attenuated double-deleted (LADD) Listeria monocytogenes $(\mathrm{Lm})$ platform can encode and deliver multiple heterologous tumor antigens to induce innate and adaptive immune responses [23]. The deletion of the genes encoding the actin assembly-inducing protein (actA) and internalin B from the $\mathrm{Lm}$ chromosome leads to $1 / 1000$ of the virulence without decreasing antigenicity [23]. Lmencoded antigens are processed via major MHC class I and class II antigen-processing pathways. Additionally, Lmbased immunotherapies can inhibit the immunosuppressive efficacy of Tregs and MDSCs in the tumor microenvironment [24-26]. In preclinical models, $L m$-based vaccination drives antigen-specific $\mathrm{T}$ cell expansion and remodeling of the tumor microenvironment [27] without upregulation of the inhibitory PD-1 checkpoint molecule (Nirschl and Drake, to be submitted for publication). Taken together, LADD $L m$-based therapeutics have the potential to deliver tumor-specific antigens, enhance immune responses, and overcome immune evasion mechanisms in mCRPC and other tumors [26].

JNJ-64041809 (JNJ-809) is a LADD Lm-based immunotherapy that encodes and expresses 4 antigens relevant to prostate cancer: prostatic acid phosphatase (PAP) [28], prostate-specific membrane antigen (PSMA) [29], synovial sarcoma X breakpoint 2 (SSX2) [30, 31], and homeobox protein NKX3.1 [32-34]. With regards to these antigens, PAP is secreted by both benign and malignant prostate columnar epithelium cells and is the target antigen for sipuleucel-T [35]. PSMA is highly expressed in prostate cancers, and the increased expression of PSMA correlates with higher grade malignancies, metastatic disease, and CRPC [29]. SSX2, a prostate cancer-testis antigen, is relatively overexpressed in metastatic prostate cancer as compared with localized prostate cancer or healthy prostate samples [30, 31]. The potential of SSX2 as an immune target is supported by immunoglobulin $\mathrm{G}$ (IgG) responses and CD8 + T cells specific for SSX2 observed in patients with prostate cancer $[30,31]$. The homeobox protein NKX3.1 is involved in the development, differentiation, and function of the prostate [32-34]. NKX3.1 is a marker of castration-resistant luminal epithelial cells and is required for the emergence of CRPC in animal models [34]. These data suggest that castration-resistant NKX3.1-expressing cells may serve as stem cells and give rise to advanced disease $[34,36]$. To evaluate the safety and immunogenicity of JNJ-809, we conducted a first-in-human phase 1 study in patients with mCRPC.

\section{Methods}

\section{Study design}

The study protocol and amendments were approved by the institutional review board at each of the sites. The study was conducted in accordance with the ethical principles that have their origin in the Declaration of Helsinki and that are consistent with Good Clinical Practices and applicable regulatory requirements. All patients or their legally acceptable representatives provided written consent to participate in the study after having been informed about the nature and purpose of the study, participation/termination conditions, and risks and benefits of treatment. This study was registered at ClinicalTrials.gov, NCT02625857. 
This was a first-in-human, phase 1, open-label, multicenter, two-part study in patients with mCRPC. Key eligibility criteria included men aged 18 years or older who had histologically confirmed metastatic prostate cancer; received at least 2 prior therapies in the castration-resistant setting; ongoing androgen deprivation therapy; serum testosterone levels $<50 \mathrm{ng} / \mathrm{dL}$ within 4 weeks prior to start of study drug; Eastern Cooperative Oncology Group (ECOG) performance status of $0-1$; adequate baseline organ function; and no history of major implants or devices (added in a protocol amendment). For cohort $2 \mathrm{~B}$, patients were required to have a primary tumor or metastatic lesion(s) amenable to tumor biopsies.

The primary objective of part 1 dose escalation was to determine the recommended phase 2 dose (RP2D) of JNJ809. The primary objective of part 2 dose expansion was to characterize the safety and immunological efficacy of JNJ809 at the RP2D in 2 expansion cohorts: cohort 2A (mCRPC) and cohort 2B (mCRPC with lesions amenable to tumor biopsies). Key secondary objectives included evaluating preliminary clinical efficacy and assessing the blood culture and shedding profile of JNJ-809; exploratory objectives included evaluating other aspects of immunologic efficacy and pharmacodynamic biomarkers.

Two dose levels of JNJ-809, intravenous $1 \times 10^{8}$ or $1 \times$ $10^{9}$ colony-forming units (CFUs) once every 21 days, were explored sequentially in part 1 using a $3+3$ design. The doses were selected based on previous clinical experience with CRS-207, another $L m$-based vaccine expressing human mesothelin, where the $1 \times 10^{8}$ and $1 \times 10^{9} \mathrm{CFU}$ doses were tolerable, and $1 \times 10^{9} \mathrm{CFU}$ was identified as the maximum tolerated dose after a dose-limiting toxicity (DLT) was reported at the $1 \times 10^{10} \mathrm{CFU}$ dose [37]. Selection of the RP2D was based on safety and pharmacodynamic assessments of innate immune responses, including lymphocyte counts and cytokine release. In part 2 dose expansion, cohorts $2 \mathrm{~A}$ and $2 \mathrm{~B}$ were administered JNJ-809 at the RP2D. Patients continued to receive treatment until (1) both prostate-specific antigen progression and radiographic progression were documented, or (2) clinical progression, or (3) physician's decision to start new anti-cancer therapy. Progression was based on Prostate Cancer Clinical Trials Working Group 2 (PCWG2) criteria [38]

\section{Study evaluations}

Safety was assessed by physical examinations, ECOG performance status, laboratory tests, vital signs, electrocardiograms, AEs, and concomitant medication usage. The DLT evaluation period was the first 21 days after the start of the first infusion. AEs were graded according to the National Cancer Institute Common Terminology Criteria for Adverse Events, v. 4.03.
Efficacy was assessed by the investigator according to (PCWG2) criteria [38] and Response Evaluation Criteria in Solid Tumors (RECIST), v. 1.1.

Peripheral blood samples were collected to evaluate the pharmacokinetics of JNJ-809 at cycle 1 day 1 (prior to infusion), 2, 4, 24, and $48 \mathrm{~h}$ after the end of the first infusion, cycle 1 day 7 , cycle 1 day 14, cycle 2 day 1 (prior to infusion), and prior to each infusion in which a disease assessment occurred. Feces, urine, and saliva were collected at similar time points to the pharmacokinetic samples above and at the end of treatment and follow-up visits to assess potential shedding of JNJ-809. Patients were required to receive prophylactic antibiotics (intravenous amoxicillin $500 \mathrm{mg}$ thrice daily (or oral trimethoprim $160 \mathrm{mg}$ and sulfamethoxazole $800 \mathrm{mg}$ twice daily for patients with penicillin allergy)) for 7 days after discontinuation of treatment.

Biomarker analyses, including interferon- $\gamma$ (IFN- $\gamma$ ) enzyme-linked immunospot (ELISpot) and flow cytometry for intracellular cytokine staining and markers of $\mathrm{T}$ cell activation, were performed using blood samples. Peripheral blood mononuclear cell (PBMC) collection and isolation were performed at each clinical site while antigen-specific $\mathrm{T}$ cell responses were evaluated centrally. The predefined quality control for ELISpot analysis was performed centrally and based on sufficient number of cells for the analysis, available baseline and at least one post-treatment sample from each patient, and a minimum viability threshold of $75 \%$ and recovery threshold of $50 \%$. Samples that did not meet these criteria were excluded from the analysis. The positivity cutoff for ELISpot analysis was defined as the background subtracted response at any point following immunotherapy minus the background subtracted response at screening being greater than 1.5 times the standard deviation of the baseline antigen-specific response or at least 10 spot-forming units per $10^{6}$ PBMC or greater. To evaluate induction of an antitumor response, pre- and post-treatment tumor biopsies of metastatic lesions were stained by immunohistochemistry (IHC) for the expression of markers associated with immune infiltrate using relevant assays.

\section{Statistical methods}

The all-treated analysis population consisted of those patients who received at least 1 dose of study agent; this population was used for all efficacy and safety analyses. The biomarker analysis population consisted of all patients who received at least 1 dose of study agent and had at least 1 pre- and post-treatment evaluable biomarker measurement.

For part 1, up to 10 patients were to be treated at each dose. For part 2, approximately 20 and 10 patients were to be enrolled in cohorts $2 \mathrm{~A}$ and $2 \mathrm{~B}$, respectively. A sample 
size of 20 would provide a two-sided $95 \%$ confidence interval of $27-73 \%$ assuming that at least $50 \%$ of patients developed a relevant antigen-specific $\mathrm{T}$ cell response.

Data were summarized using descriptive statistics. Continuous variables included number of observations, mean, standard deviation, median, and range. Categorical values were summarized using number of observations and percentages.

\section{Results}

Between 16 December 2015 and 3 July 2018, 26 men with mCRPC were enrolled in the study; 12 patients in part 1 (6 at $1 \times 10^{8} \mathrm{CFU}$ and 6 at $\left.1 \times 10^{9} \mathrm{CFU}\right)$ and 14 patients in part 2 ( 6 in cohort $2 \mathrm{~A}$ and 8 in cohort $2 \mathrm{~B}$ ). The median age was 67 years (range, 46-85), and the majority of patients were white $(96 \%$; Table 1). The median time from initial diagnosis to first dose of study agent was 6 years (range, 1-18). The majority of patients had Gleason score $\geq 8$ (62\%), $27 \%$ had bone-only disease, and $62 \%$ had soft tissue or node disease (Table 1). Seventeen patients had received prior first-generation androgen receptor therapies (bicalutamide, nilutamide, flutamide), 3 patients had received prior secondgeneration or later androgen receptor therapy (abiraterone or enzalutamide), and 4 had received prior taxane therapy.

All 26 patients discontinued study treatment. Progressive disease was the most common reason for discontinuation (81\%), followed by patient withdrawal (12\%), AE (4\%), and treatment discontinuation because of major indwelling hardware implant, which was a new exclusion criterion in the amended protocol (4\%; Supplementary Fig. 1). The median duration of study treatment was 2.5 months (range, $0-10)$. The study was terminated early as data collected from 26 patients was sufficient to evaluate safety and immunogenicity of JNJ-809.

No DLTs were reported during dose escalation, and $1 \times$ $10^{9} \mathrm{CFU}$ was selected as the RP2D. AEs were consistent across both parts 1 and 2, and all patients reported AEs that were related to study treatment (Table 2). One patient experienced grade 3 small intestinal obstruction which led to discontinuation of study treatment; the small intestinal obstruction was not related to study treatment. The most frequently reported AEs were chills (92\%), pyrexia (81\%), and fatigue (62\%; Table 2). The chills and pyrexia, which resolved within $48 \mathrm{~h}$ and were consistent with transient activation of the innate immune response to JNJ-809, were managed with supportive care during the required observation period in the outpatient setting. Grade $\geq 3 \mathrm{AEs}$ were reported in $69 \%$ of patients; lymphopenia (27\%) and hypertension (23\%) were most frequent and were generally transient, resolving within 1-4 days. Seven (27\%) patients had serious AEs, including 1 patient with pelvic pain, penile
Table 1 Demographic and baseline disease characteristics.

\begin{tabular}{|c|c|c|c|}
\hline & $\begin{array}{l}1 \times 10^{8} \mathrm{CFU} \\
n=6\end{array}$ & $\begin{array}{l}1 \times 10^{9} \mathrm{CFU} \\
n=20\end{array}$ & $\begin{array}{l}\text { Total } \\
n=26\end{array}$ \\
\hline $\begin{array}{l}\text { Median age, years } \\
\text { (range) }\end{array}$ & $74(58-77)$ & $65(46-85)$ & $67(46-85)$ \\
\hline \multicolumn{4}{|l|}{ Race, $n(\%)$} \\
\hline White & $5(83)$ & $20(100)$ & $25(96)$ \\
\hline $\begin{array}{l}\text { Black or African } \\
\text { American }\end{array}$ & $1(17)$ & 0 & $1(4)$ \\
\hline \multicolumn{4}{|l|}{ ECOG PS, $n(\%)$} \\
\hline 0 & $2(33)$ & $7(35)$ & $9(35)$ \\
\hline 1 & $4(67)$ & $13(65)$ & $17(65)$ \\
\hline $\begin{array}{l}\text { Time from initial } \\
\text { diagnosis, years (range) }\end{array}$ & $5(1-18)$ & $6(1-17)$ & $6(1-18)$ \\
\hline \multicolumn{4}{|l|}{ Gleason score, $n(\%)$} \\
\hline$<7$ & $1(17)$ & $2(10)$ & $3(12)$ \\
\hline 7 & $2(33)$ & $3(15)$ & $5(19)$ \\
\hline$\geq 8$ & $3(50)$ & $13(65)$ & $16(62)$ \\
\hline Unknown & 0 & $2(10)$ & $2(8)$ \\
\hline \multicolumn{4}{|c|}{ Extent of disease at entry, $n(\%)$} \\
\hline Bone & $4(67)$ & $19(95)$ & $23(89)$ \\
\hline Bone only & $1(17)$ & $6(30)$ & $7(27)$ \\
\hline Soft tissue or node & $2(33)$ & $14(70)$ & $16(62)$ \\
\hline Other & $3(50)$ & $5(25)$ & $8(31)$ \\
\hline \multicolumn{4}{|c|}{ Evidence of disease progression, $n(\%)$} \\
\hline PSA & 0 & $14(74)$ & $14(56)$ \\
\hline Radiographic & $6(100)$ & $11(58)$ & $17(68)$ \\
\hline \multicolumn{4}{|l|}{ Laboratory parameters } \\
\hline $\begin{array}{l}\text { Median hemoglobin, } \\
\mathrm{g} / \mathrm{dL} \text { (range) }\end{array}$ & $10(9-13)$ & $11(9-14)$ & $11(9-14)$ \\
\hline $\begin{array}{l}\text { Median alkaline } \\
\text { phosphatase, U/L } \\
\text { (range) }\end{array}$ & $178(74-633)$ & $\begin{array}{l}88 \\
(25-1015)\end{array}$ & $\begin{array}{l}96 \\
(25-1015)\end{array}$ \\
\hline $\begin{array}{l}\text { Median lactate } \\
\text { dehydrogenase, U/L } \\
\text { (range) }\end{array}$ & $\begin{array}{l}849 \\
(314-2719)\end{array}$ & $\begin{array}{l}370 \\
(99-2203)\end{array}$ & $\begin{array}{l}401 \\
(99-2719)\end{array}$ \\
\hline
\end{tabular}

$C F U$ colony-forming unit, ECOG PS Eastern Cooperative Oncology Group performance status, PSA prostate-specific antigen.

pain, and rectal pain and another patient with large intestinal obstruction and large intestine perforation, with the latter being assessed by the investigator as related to JNJ-809. However, the sponsor considered these events not related to study treatment because of the patient's history of prior radiation to the area, and the large intestine perforation occurred in the setting of colonic stent erosion with diffuse peritonitis. The other 5 patients had a single serious AE of spinal cord compression, gastrointestinal hemorrhage, confusional state, small intestinal obstruction, or neuralgia.

LADD $L m$ bacteremia was monitored by both aerobic and anaerobic cultures of blood samples at specified time points following infusion. All 6 patients who received $1 \times$ $10^{8} \mathrm{CFU}$ had negative blood cultures for LADD $\mathrm{Lm}$ at each 
Table 2 Adverse events.

\begin{tabular}{|c|c|c|c|}
\hline AEs, $n(\%)$ & $\begin{array}{l}1 \times 10^{8} \mathrm{CFU} \\
n=6\end{array}$ & $\begin{array}{l}1 \times 10^{9} \mathrm{CFU} \\
n=20\end{array}$ & $\begin{array}{l}\text { Total } \\
n=26\end{array}$ \\
\hline Any AEs & $6(100)$ & $20(100)$ & $26(100)$ \\
\hline Related AEs & $6(100)$ & $20(100)$ & $26(100)$ \\
\hline Grade $\geq 3$ AEs & $5(83)$ & $13(65)$ & $18(69)$ \\
\hline Related grade $\geq 3$ AEs & $3(50)$ & $8(40)$ & $11(42)$ \\
\hline Serious AEs & $2(33)$ & $5(25)$ & $7(27)$ \\
\hline Related serious AEs & 0 & $1(5)$ & $1(4)$ \\
\hline Grade $\geq 3$ serious AEs & $2(33)$ & $4(20)$ & $6(23)$ \\
\hline $\begin{array}{l}\text { AEs leading to treatment } \\
\text { discontinuation }\end{array}$ & 0 & $1(5)$ & $1(4)$ \\
\hline \multicolumn{4}{|c|}{ Most common AEs ( $\geq 20 \%$ of total), $n(\%)$} \\
\hline Chills & $5(83)$ & $19(95)$ & $24(92)$ \\
\hline Pyrexia & $5(83)$ & $16(80)$ & $21(81)$ \\
\hline Fatigue & $4(67)$ & $12(60)$ & $16(62)$ \\
\hline Nausea & $3(50)$ & $9(45)$ & $12(46)$ \\
\hline Vomiting & $2(33)$ & $9(45)$ & $11(42)$ \\
\hline Anemia & $4(67)$ & $7(35)$ & $11(42)$ \\
\hline Arthralgia & $3(50)$ & $7(35)$ & $10(39)$ \\
\hline Decreased appetite & $1(17)$ & $7(35)$ & $8(31)$ \\
\hline Constipation & $3(50)$ & $4(20)$ & $7(27)$ \\
\hline Back pain & $2(33)$ & $5(25)$ & $7(27)$ \\
\hline Lymphopenia & $1(17)$ & $6(30)$ & $7(27)$ \\
\hline Hypertension & $1(17)$ & $6(30)$ & $7(27)$ \\
\hline Diarrhea & $3(50)$ & $3(15)$ & $6(23)$ \\
\hline Headache & $1(17)$ & $5(25)$ & $6(23)$ \\
\hline
\end{tabular}

$A E$ adverse event, $C F U$ colony-forming unit.

time point tested. For the 20 patients treated with $1 \times 10^{9}$ $\mathrm{CFU}$, at cycle 1 day $1,2 \mathrm{~h}$ postdose, 4 patients had both aerobic and anaerobic blood cultures that were positive for LADD $L m 2 \mathrm{~h}$ postdose, and 1 patient had only a positive aerobic blood culture and another patient had only a positive anaerobic blood culture. At $4 \mathrm{~h}$ postdose, only 1 patient had an aerobic blood culture that remained positive for LADD Lm. However, all subsequent blood cultures were negative for LADD $\mathrm{Lm}$ for all patients. No fecal, urine, or saliva samples were positive for LADD $\mathrm{Lm}$.

Twenty-five of the 26 enrolled patients had measurable disease at baseline and could be assessed for objective response by RECIST. The best overall response was stable disease (SD) in 13 of 25 (52\%) response-evaluable patients; 11 patients had SD for $\geq 12$ weeks, and 6 patients had SD for $\geq 16$ weeks (Supplementary Fig. S2). Nine (36\%) patients had progressive disease, and $3(12 \%)$ were not evaluable due to the lack of post-treatment response assessment (Table 3).

Of the 7 paired biopsies that were collected, 3 did not have sufficient tumor tissue for analysis (in the pre- and/or post-treatment biopsies), and 4 were evaluable for CD8 and
Table 3 Best overall response.

\begin{tabular}{|c|c|c|c|}
\hline $\begin{array}{l}\text { Best overall response, } \\
n(\%)\end{array}$ & $\begin{array}{l}1 \times 10^{8} \mathrm{CFU} \\
n=6\end{array}$ & $\begin{array}{l}1 \times 10^{9} \mathrm{CFU} \\
n=19\end{array}$ & $\begin{array}{l}\text { Total } \\
n=25^{\text {a }}\end{array}$ \\
\hline Stable disease & $3(50)$ & $10(53)$ & $13(52)$ \\
\hline Progressive disease & $2(33)$ & $7(37)$ & $9(36)$ \\
\hline Non-evaluable ${ }^{b}$ & $1(17)$ & $2(11)$ & $3(12)$ \\
\hline
\end{tabular}

${ }^{\mathrm{a} O n l y} 25$ patients had measurable disease at baseline and were evaluable for response per RECIST.

${ }^{\mathrm{b}}$ Three patients were not evaluable by RECIST due to the absence of radiographic progression.

$C F U$ colony-forming unit.

FOXP3 IHC staining. In 3 pairs of pre- and post-treatment biopsies, CD8 + cells and FOXP3 + cells either decreased, remained unchanged, or increased. In one biopsy pair, CD8 + cells increased and FOXP3 + cells were unchanged. Results were considered inconclusive, given the variability and the low number of evaluable samples available for analysis.

Innate immune responses were demonstrated in all patients at both doses. Transient increases in levels of serum pro-inflammatory cytokines IFN- $\gamma$, tumor necrosis factor alpha (TNF $\alpha$ ), and interleukin-10 (IL-10) were greatest $24 \mathrm{~h}$ after JNJ-809 infusion and returned to baseline by $48 \mathrm{~h}$ after infusion (Fig. 1A-C). Lymphocyte activation was also observed after treatment with JNJ-809 (Fig. 1D).

Adaptive immune responses were assessed by quantifying antigen-specific $\mathrm{T}$ cell responses using ELISpot analysis. Seven of the 26 patients had PBMCs that met the predefined quality-control criteria for ELISpot analysis. All 7 patients showed $\mathrm{T}$ cell responses to the cytomegalovirus, Epstein-Barr virus, influenza, and tetanus toxoid (CEFT) positive control epitopes, and 6 patients demonstrated reactivity to the Listeria antigen listeriolysin O (LLO) in at least one post-treatment assessment (Fig. 2). Post-treatment $\mathrm{T}$ cell responses to at least 1 of the 4 encoded tumorassociated antigens were observed in 5 patients, with no specific tumor antigen demonstrating superior responses over the others (Fig. 2). Although the antigen-specific T cell responses were variable in magnitude and persistence, they were consistently lower than the responses to LLO and CEFT (Fig. 2).

\section{Discussion}

In this first-in-human study of JNJ-809 in men with mCRPC, the safety profiles of the $1 \times 10^{8}$ and $1 \times 10^{9} \mathrm{CFU}$ doses were comparable and consistent with those reported for LADD-based immunotherapeutics [37, 39, 40]. Across both doses, SD was the best overall response achieved among the response-evaluable patients. 



The most commonly reported AEs were chills (92\%) and pyrexia $(81 \%)$, the severity and incidence of which did not appear to be associated with JNJ-809 dose, although this
Fig. 1 Release of serum cytokines following JNJ-809 infusion. Transient increases in pro-inflammatory serum cytokines: A IFN- $\gamma$, B TNF $\alpha$, and C IL-10 were observed after treatment with both $1 \times 10^{8}$ CFU (top) and $1 \times 10^{9}$ CFU (bottom) doses of JNJ-809. D Lymphocyte activation was observed following treatment with JNJ-809 at $1 \times$ $10^{8} \mathrm{CFU}$ (top) and $1 \times 10^{9} \mathrm{CFU}$ (bottom) doses. CFU $=$ colonyforming unit; IFN $=$ interferon; IL-10 $=$ interleukin-10; $\mathrm{TNF}=$ tumor necrosis factor.

comparison is limited by the small number of patients in the study. One patient had serious adverse events of large intestinal obstruction and large intestine perforation which were considered to be study drug-related by the investigator. However, because the large intestine perforation was observed in the context of erosion of stents placed to treat colonic obstruction, the sponsor considered these events not related to study treatment.

The risk of LADD $\mathrm{Lm}$ bacteremia was evaluated through blood cultures and shedding samples. All 6 patients who received JNJ-809 doses of $1 \times 10^{8} \mathrm{CFU}$ had negative blood cultures for LADD $\mathrm{Lm}$ at each time point tested. A number of patients who received JNJ-809 doses of $1 \times 10^{9} \mathrm{CFU}$ had transient positive blood cultures on the day of drug administration, but all subsequent blood cultures from these patients were negative for LADD Lm. Additionally, all blood cultures tested at the end of treatment (before the start of the required post-treatment antibiotic therapy) and at long-term follow-up (every 3 months after the end of treatment) were negative for LADD $\mathrm{Lm}$. None of the fecal, urine, or saliva samples from patients treated at either dose tested positive for LADD $\mathrm{Lm}$. These data suggest that although JNJ-809 is administered intravenously, the bacteria are cleared from the systemic circulation quickly, and the risk of persistent bacteremia or inter-person transmission is low. The risk is further lowered with a required course of antibiotics and for those patients with a central venous catheter (e.g., Port-a-Cath or Mediport), the first dose of antibiotics was given through the port.

Consistent with reports of other LADD therapeutics [40], cytokine and chemokine release after JNJ-809 administration were transient and peaked approximately $24 \mathrm{~h}$ after the end of infusion before returning to baseline levels within 48-72 $\mathrm{h}$. This cytokine release profile coincided with reported chills and pyrexia, which resolved within $48 \mathrm{~h}$ and was consistent with activation of innate immunity.

ELISpot biomarker data were limited ( 7 of 26 patients) due to inadequate quality of PBMC processing at some sites. Specifically, a number of samples failed to meet the predefined quality-control criteria based on cell viability and recovery, and issues related to sample handling and processing were identified centrally when samples were processed for ELISpot analysis. This highlights the importance of ensuring sites are proficient in PBMC processing and establishing pre-analytical sample quality controls to 
A.

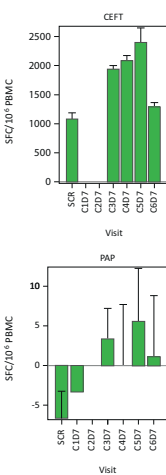

B.

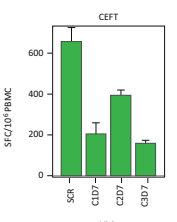

vist

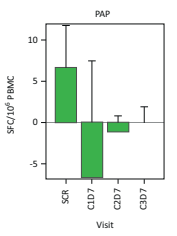

C.
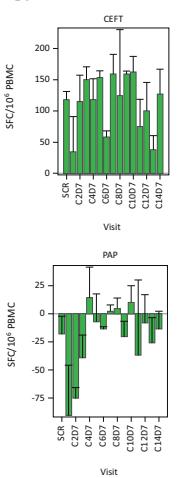

Patient 302

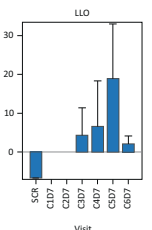

vist



vast



visit



visit

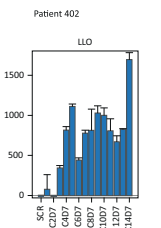

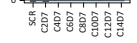





D.
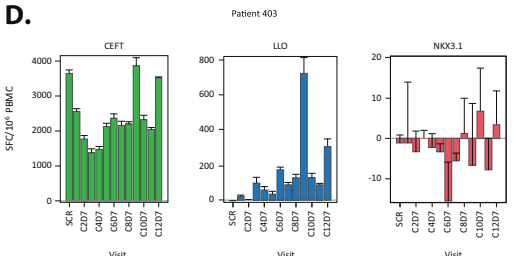

vist


E.

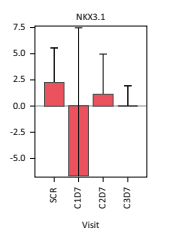

E.


F.


G.
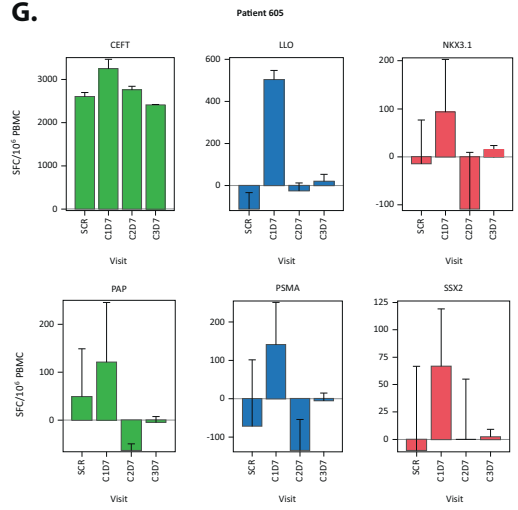

Fig. 2 ELISpot analysis of tumor-associated antigens. ELISpot analyses are shown for all 7 patients $(\mathbf{A}-\mathbf{G})$ who had evaluable samples. Error bars represent the standard deviation of 3 replicates for each ELISpot. $\mathrm{C}=$ cycle; $\mathrm{CEFT}=$ cytomegalovirus, Epstein-Barr virus, influenza, and tetanus toxoid; $\mathrm{D}=$ day; $\mathrm{LLO}=$ listeriolysin $\mathrm{O} ; \mathrm{PAP}=$

prostatic acid phosphatase; $\mathrm{PBMC}=$ peripheral blood mononuclear cell; PSMA = prostate-specific membrane antigen; $\mathrm{SCR}=$ screening; $\mathrm{SFC}=$ spot forming colonies; $\mathrm{SSX}-2=$ synovial sarcoma $\mathrm{X}$ chromosome breakpoint- 2 . 
allow for timely identification of potential sample quality issues at the site level and implementation of corrective measures. Although the number of samples was small and ELISpot responses were variable in magnitude and persistence, the results indicate that antigen-specific $\mathrm{T}$ cell responses to the JNJ-809-encoded antigen LLO can be reliably elicited.

The study was terminated early as data collected from the 26 patients enrolled in the study were sufficient to evaluate safety and immunogenicity. During the course of the study, a Janssen clinical hold was placed on the LADD platform due to concerns of Listeria persistence in another Janssensponsored LADD study [40]. Additionally, in this study, ELISpot analysis failed to demonstrate robust evidence of adaptive immune response either due to improperly processed samples or failure of JNJ-809 to elicit a response to targeted prostate cancer antigens, despite the ability to elicit LLO responses. Based on the lack of immunogenic and clinical response data up until that point, and in the context of other Janssen-sponsored LADD studies, the strategic decision was made to stop the study due to the low likelihood of demonstrating the primary endpoint.

In conclusion, the safety profile of JNJ-809 was similar across both doses evaluated and is consistent with other LADD-based therapeutics [37, 39]. Activation of innate and acquired immune responses were observed following JNJ809 monotherapy; however, the sample size was relatively small, and the magnitude of immune responses was modest with no clear clinical benefit demonstrated for monotherapy. Having demonstrated safety, intervention at earlier stages of cancer may result in more robust responses.

Acknowledgements The authors thank the study participants, without whom this study would never have been accomplished and the investigators for their participation in the studies that provided these data. Medical writing was provided by Tracy T. Cao, PhD (Janssen Global Services, LLC) and funded by Janssen Global Services, LLC.

Author contributions C.G.D., R.K.P., S.K.S., D.G.M., E.S.A., T.M. B., and L.F. were involved in data acquisition and analysis, interpretation, and review of the data. P.L. led the design and construction of the vector. D.B. was involved in developing the design and construction of the vector. D.A.P. was involved in data acquisition, reporting, and interpretation. S.G. was involved in study design and data collection. R.E.K. was involved in study design, execution of the study, and review and analysis of data. G.E.M., D.P., M.W., E.Z., N. B., N.S., J.R.I., and M.M.G were involved in execution of the study, and review and analysis of data. All authors contributed to writing of the manuscript. All authors had full access to all the data in the study and take responsibility for the integrity of the data and the accuracy of the data analysis.

Funding and role of sponsor This study was funded by Janssen Research \& Development, LLC. The sponsor was involved in the design and conduct of the study; collection, management, analysis, and interpretation of the data; and preparation, review, and approval of the manuscript.

\section{Compliance with ethical standards}

Conflict of interest C.G.D. is a current employee of Janssen R\&D and reports prior consulting or advisory role for AstraZeneca/MedImmune, Bristol-Myers Squibb, Compugen, Roche/Genentech, Janssen Oncology, Pfizer, Tizona Therapeutics, Inc., Potenza Therapeutics, Merck, Rubius, and Pierre Fabre; travel, accommodation, expenses from Roche/Genentech, AACR, ASCO, Merck Sharp \& Dohme, and Pfizer; patents licensed from Johns Hopkins to Bristol-Myers Squibb; stock and other ownership interests in Compugen, Tizona Therapeutics, Inc., Harpoon Therapeutics, and Kleo Pharmaceuticals; and research funding to Johns Hopkins from Bristol-Myers Squibb. R.K.P. reports consulting or advisory role for EMD Serono, Bristol-Myers Squibb, Pfizer/EMD Serono, Sanofi, Jounce Therapeutics, Dendreon, Bayer, and Genomic Health; speakers' bureau for Dendreon, Merck, Genentech/Roche, AstraZeneca, Sanofi, and Genomic Health; travel, accommodations, expenses from Genentech/Roche, DAVA Oncology; and research funding from Janssen Oncology. S.K.S. reports consulting or advisory role for Amgen, Apricity Health, AstraZeneca, Bayer, Bristol-Myers Squibb, Dava Oncology, Dendreon, Exelixis, Janssen Oncology, and Polaris; travel, accommodations, expenses from AstraZeneca, Bristol-Myers Squibb, Dava Oncology, Dendreon, Parker Institute of Cancer Immunotherapy, and Society for Immunotherapy of Cancer; stock or other ownership in Apricity Health; honoraria from AstraZeneca, Bristol-Myers Squibb, Dava Oncology, Dendreon, Parker Institute of Cancer Immunotherapy, and Society for Immunotherapy of Cancer; and research funding to his institution from AstraZeneca, Bristol-Myers Squibb, and Janssen Oncology. D.G.M. reports consulting or advisory role for Madison Vaccines, Inc.; leadership role for Madison Vaccines, Inc.; travel, accommodations, expenses from Madison Vaccines, Inc., patents licensed from his institution to Madison Vaccines, Inc.; stock and other ownership interests in Madison Vaccines, Inc.; research funding to his institution from Madison Vaccines, Inc. and from Janssen, Bristol-Myers Squibb, Pfizer, Merck, and Novartis. E.S.A. reports consulting or advisory role for Sanofi, Dendreon, Medivation, Janssen Biotech, ESSA, Astellas Pharma, Merck, AstraZeneca, and Clovis Oncology; travel, accommodations, expenses from Sanofi, Dendreon, and Medivation; coinventor of a biomarker technology that has been licensed to Qiagen; honoraria from Sanofi, Dendreon, Medivation, Janssen Biotech, ESSA, Astellas Pharma, Merck, AstraZeneca, and Clovis Oncology; research funding to his institution from Janssen Biotech, Johnson \& Johnson, Sanofi, Dendreon, Aragon Pharmaceuticals, Exelixis, Millennium, Genentech, Novartis, Astellas Pharma, Tokai Pharmaceuticals, Merck, AstraZeneca, Clovis Oncology, and Constellation Pharmaceuticals. T.M.B. reports employment with Tennessee Oncology; consulting or advisory role for Guardant Health, Loxo, Pfizer, and Exelixis; consulting or advisory role for his institution for Ignyta, Moderna Therapeutics, and Pfizer; speakers' bureau for Bayer; travel, accommodations, expenses from Astellas Pharma, AstraZeneca, Celgene, Clovis Oncology, EMD Serono, Genentech, Lilly, Merck, Novartis, Pharmacyclics, and Sysmex; research funding to his institution from Daiichi Sankyo, Medpacto, Inc., Incyte, Mirati Therapeutics, MedImmune, AbbVie, AstraZeneca, Leap Therapeutics, MabVax, Stemline Therapeutics, Merck, Lilly, GlaxoSmithKline, Novartis, Pfizer, Genentech/Roche, Deciphera, Merrimack, Immunogen, Millennium, Ignyta, Calithera Biosciences, Kolltan Pharmaceuticals, Principa Biopharma, Peleton, Immunocore, Roche, Aileron Therapeutics, Bristol-Myers Squibb, Amgen, Moderna Therapeutics, Sanofi, Boehringer Ingelheim, Astellas Pharma, Five Prime Therapeutics, Jacobio, Top Alliance BioScience, Loxo, Janssen, Clovis Oncology, Takeda, Karyopharm Therapeutics, Onyx, Phosplatin Therapeutics, Foundation Medicine, and ARMO BioSciences. P.L. and Dr. D.B. report former employment with Aduro Biotech. D.P., M.W., E.Z., N.B., D.A.P., S.G., G.E.M., R.E.K., N.S., J.R.I., and 
M.M.G. report employment with Janssen R\&D and stock or other ownership in Johnson \& Johnson. L.F. reports consulting or advisory role for Atreca, Nutcracker Therapeutics, Inc., Bolt Biotherapeutics, BioAtla, and TeneoBio and research funding to his institution from Bristol-Myers Squibb, AbbVie, Roche/Genentech, Janssen Oncology, Merck, Bavarian Nordic, and Dendreon.

Data sharing statement The data sharing policy of Janssen Pharmaceutical Companies of Johnson \& Johnson is available at https://www. janssen.com/clinical-trials/transparency. As noted on this site, requests for access to the study data can be submitted through Yale Open Data Access (YODA) Project site at http://yoda.yale.edu.

Publisher's note Springer Nature remains neutral with regard to jurisdictional claims in published maps and institutional affiliations.

Open Access This article is licensed under a Creative Commons Attribution 4.0 International License, which permits use, sharing, adaptation, distribution and reproduction in any medium or format, as long as you give appropriate credit to the original author(s) and the source, provide a link to the Creative Commons license, and indicate if changes were made. The images or other third party material in this article are included in the article's Creative Commons license, unless indicated otherwise in a credit line to the material. If material is not included in the article's Creative Commons license and your intended use is not permitted by statutory regulation or exceeds the permitted use, you will need to obtain permission directly from the copyright holder. To view a copy of this license, visit http://creativecommons. org/licenses/by/4.0/.

\section{References}

1. Bray F, Ferlay J, Soerjomataram I, Siegel RL, Torre LA, Jemal A. Global cancer statistics 2018: GLOBOCAN estimates of incidence and mortality worldwide for 36 cancers in 185 countries. CA Cancer J Clin. 2018;68:394-424.

2. Amling CL, Blute ML, Bergstralh EJ, Seay TM, Slezak J, Zincke H. Long-term hazard of progression after radical prostatectomy for clinically localized prostate cancer: continued risk of biochemical failure after 5 years. J Urol. 2000;164:101-5.

3. Roehl KA, Han M, Ramos CG, Antenor JA, Catalona WJ. Cancer progression and survival rates following anatomical radical retropubic prostatectomy in 3,478 consecutive patients: long-term results. J Urol. 2004;172:910-4.

4. Artibani W, Porcaro AB, De Marco V, Cerruto MA, Siracusano S. Management of biochemical recurrence after primary curative treatment for prostate cancer: a review. Urol Int. 2018;100:251-62.

5. Finianos A, Gupta K, Clark B, Simmens SJ, Aragon-Ching JB. haracterization of differences between prostate cancer patients presenting with de novo versus primary progressive metastatic disease.Clin Genitourin Cancer. 2018;16:85-9.

6. Mosillo C, Iacovelli R, Ciccarese C, Fantinel E, Bimbatti D, Brunelli $\mathrm{M}$, et al. De novo metastatic castration sensitive prostate cancer: state of art and future perspectives. Cancer Treat Rev. 2018;70:67-74.

7. Beer TM, Armstrong AJ, Rathkopf DE, Loriot Y, Sternberg CN, Higano CS, et al. Enzalutamide in metastatic prostate cancer before chemotherapy. N. Engl J Med. 2014;371:424-33.

8. de Bono JS, Logothetis CJ, Molina A, Fizazi K, North S, Chu L, et al. Abiraterone and increased survival in metastatic prostate cancer. N Engl J Med. 2011;364:1995-2005.

9. Fizazi K, Scher HI, Molina A, Logothetis CJ, Chi KN, Jones RJ, et al. Abiraterone acetate for treatment of metastatic castration-resistant prostate cancer: final overall survival analysis of the COU-AA-301 randomised, double-blind, placebocontrolled phase 3 study. Lancet Oncol. 2012;13:983-92.

10. Scher HI, Fizazi K, Saad F, Taplin ME, Sternberg CN, Miller K, et al. Increased survival with enzalutamide in prostate cancer after chemotherapy. N Engl J Med. 2012;367:1187-97.

11. Antonarakis ES, Lu C, Wang H, Luber B, Nakazawa M, Roeser $\mathrm{JC}$, et al. AR-V7 and resistance to enzalutamide and abiraterone in prostate cancer. N Engl J Med. 2014;371:1028-38.

12. Arora VK, Schenkein E, Murali R, Subudhi SK, Wongvipat J, Balbas MD, et al. Glucocorticoid receptor confers resistance to antiandrogens by bypassing androgen receptor blockade. Cell. 2013;155:1309-22.

13. Silberstein JL, Taylor MN, Antonarakis ES. Novel insights into molecular indicators of response and resistance to modern androgen-axis therapies in prostate cancer. Curr Urol Rep. 2016;17:29.

14. Dendreon. PROVENGE: Highlights of prescribing information. Dendreon; 2017.

15. Merck \& Co. Inc. KEYTRUDA: Highlights of prescribing information. Merck \& Co. Inc.; 2020.

16. Calcinotto A, Spataro C, Zagato E, Di Mitri D, Gil V, Crespo M, et al. IL-23 secreted by myeloid cells drives castration-resistant prostate cancer. Nature. 2018;559:363-9.

17. Erlandsson A, Carlsson J, Lundholm M, Falt A, Andersson SO, Andren $\mathrm{O}$, et al. M2 macrophages and regulatory $\mathrm{T}$ cells in lethal prostate cancer. Prostate. 2019;79:363-9.

18. Sanda MG, Restifo NP, Walsh JC, Kawakami Y, Nelson WG, Pardoll DM, et al. Molecular characterization of defective antigen processing in human prostate cancer. $\mathbf{J}$ Natl Cancer Inst. 1995;87:280-5.

19. Su W, Han HH, Wang Y, Zhang B, Zhou B, Cheng Y, et al. The polycomb repressor complex 1 drives double-negative prostate cancer metastasis by coordinating stemness and immune suppression. Cancer Cell. 2019;36:139-55. e10

20. Beer TM, Kwon ED, Drake CG, Fizazi K, Logothetis C, Gravis $\mathrm{G}$, et al. Randomized, double-blind, phase III trial of ipilimumab versus placebo in asymptomatic or minimally symptomatic patients with metastatic chemotherapy-naive castration-resistant prostate cancer. J Clin Oncol. 2017;35:40-47.

21. Kwon ED, Drake CG, Scher HI, Fizazi K, Bossi A, van den Eertwegh AJ, et al. Ipilimumab versus placebo after radiotherapy in patients with metastatic castration-resistant prostate cancer that had progressed after docetaxel chemotherapy (CA184-043): a multicentre, randomised, double-blind, phase 3 trial. Lancet Oncol. 2014;15:700-12.

22. Topalian SL, Hodi FS, Brahmer JR, Gettinger SN, Smith DC, McDermott DF, et al. Safety, activity, and immune correlates of anti-PD-1 antibody in cancer. N Engl J Med. 2012;366:2443-54.

23. Brockstedt DG, Giedlin MA, Leong ML, Bahjat KS, Gao Y, Luckett W, et al. Listeria-based cancer vaccines that segregate immunogenicity from toxicity. Proc Natl Acad Sci USA. 2004;101:13832-7.

24. Mkrtichyan M, Chong N, Abu Eid R, Wallecha A, Singh R, Rothman J, et al. Anti-PD-1 antibody significantly increases therapeutic efficacy of Listeria monocytogenes (Lm)-LLO immunotherapy. J Immunother Cancer. 2013;1:15.

25. Wallecha A, Singh R, Malinina I. Listeria monocytogenes (Lm)LLO immunotherapies reduce the immunosuppressive activity of myeloid-derived suppressor cells and regulatory $\mathrm{T}$ cells in the tumor microenvironment. J Immunother. 2013;36:468-76.

26. Wood LM, Paterson Y. Attenuated Listeria monocytogenes: a powerful and versatile vector for the future of tumor immunotherapy. Front Cell Infect Microbiol. 2014;4:51.

27. Deng W, Lira V, Hudson TE, Lemmens EE, Hanson WG, Flores $\mathrm{R}$, et al. Recombinant Listeria promotes tumor rejection by CD8 
(+) T cell-dependent remodeling of the tumor microenvironment. Proc Natl Acad Sci USA. 2018;115:8179-84.

28. Wei XX, Fong L, Small EJ. Prostate cancer immunotherapy with Sipuleucel-T: current standards and future directions. Expert Rev Vaccines. 2015;14:1529-41.

29. Akhtar NH, Pail O, Saran A, Tyrell L, Tagawa ST. Prostatespecific membrane antigen-based therapeutics. Adv Urol. 2012;2012:973820.

30. Dubovsky JA, McNeel DG. Inducible expression of a prostate cancer-testis antigen, SSX-2, following treatment with a DNA methylation inhibitor. Prostate. 2007;67:1781-90.

31. Smith HA, Cronk RJ, Lang JM, McNeel DG. Expression and immunotherapeutic targeting of the SSX family of cancer-testis antigens in prostate cancer. Cancer Res. 2011;71:6785-95.

32. Bhatia-Gaur R, Donjacour AA, Sciavolino PJ, Kim M, Desai N, Young $\mathrm{P}$, et al. Roles for Nkx3.1 in prostate development and cancer. Genes Dev. 1999;13:966-77.

33. Kim MJ, Bhatia-Gaur R, Banach-Petrosky WA, Desai N, Wang Y, Hayward SW, et al. Nkx3.1 mutant mice recapitulate early stages of prostate carcinogenesis. Cancer Res. 2002;62:2999-3004.

34. Wang X, Kruithof-de Julio M, Economides KD, Walker D, Yu H, Halili MV, et al. A luminal epithelial stem cell that is a cell of origin for prostate cancer. Nature. 2009;461:495-500.

35. Gomella LG, Gelpi-Hammerschmidt F, Kundavram C. Practical guide to immunotherapy in castration resistant prostate cancer: the use of sipuleucel-T immunotherapy. Can J Urol. 2014;21:48-56. (2 Supp 1)

36. Xie Q, Wang ZA. Transcriptional regulation of the Nkx3.1 gene in prostate luminal stem cell specification and cancer initiation via its $3^{\prime}$ genomic region. J Biol Chem. 2017;292:13521-30.

37. Le DT, Brockstedt DG, Nir-Paz R, Hampl J, Mathur S, Nemunaitis $\mathrm{J}$, et al. A live-attenuated Listeria vaccine (ANZ-100) and a live-attenuated Listeria vaccine expressing mesothelin (CRS-207) for advanced cancers: phase I studies of safety and immune induction. Clin Cancer Res. 2012;18:858-68.

38. Scher HI, Halabi S, Tannock I, Morris M, Sternberg CN, Carducci MA, et al. Design and end points of clinical trials for patients with progressive prostate cancer and castrate levels of testosterone: recommendations of the Prostate Cancer Clinical Trials Working Group. J Clin Oncol. 2008;26:1148-59.

39. Le DT, Wang-Gillam A, Picozzi V, Greten TF, Crocenzi T, Springett G, et al. Safety and survival with GVAX pancreas prime and Listeria monocytogenes-expressing mesothelin (CRS-207) boost vaccines for metastatic pancreatic cancer. J Clin Oncol. 2015;33:1325-33.

40. Brahmer JR, Johnson ML, Cobo M, Viteri S, Sarto JC, Sukari A, et al. JNJ-64041757 (JNJ-757), a live, attenuated, double-deleted Listeria monocytogenes-based immunotherapy in patients with NSCLC: results from two phase 1 studies. JTO Clin Res Rep. 2021;2:100103. 